\title{
Essential skills for a medical teacher: an introduction to teaching and learning in medicine
}

- Title: Essential skills for a medical teacher: an introduction to teaching and learning in medicine

- Authors: Ronald M. Harden, Jennifer M. Laidlaw

- Publisher: Churchill Livingstone, 2012

- ISBN: 9780702045820

지금까지 다양한 교수법 책들이 소개되었지만 의학교육 상 황에 바로 적용할 수 있는 핵심 기술을 담고 있는 책은 많지 않았다. 이에 학습성과에서부터 교육과정, 교수학습방법, 평 가에 이르기까지 다음의 4가지 질문에 대한 실제적인 조언을 통해 의학교육을 담당하고 있는 교수들이 'good teacher'로 거듭날 수 있도록 도와주고 있는 "Essential skills for a medical teacher"을 소개하고자 한다.

(1) What should be learned or taught (the learning outcomes).

(2) How the training or learning programme can be organized (the curriculum).

(3) How students or trainees can learn most effectively (the teaching and learning methods).

(4) How the learning can be assessed.

이 책의 본문은 총 6 개의 세션으로 구성되어 있다. 첫 번째 세션 “The roles and competencies of a good teacher"은 의 학교육에 필요한 교수의 역할을 6가지 영역 -facilitator (or mentor), role model, information provider, resource developer, planner, assessor - 으로 규명하고 있으며 'good teacher'가 되기 위해서 구체적으로 어떠한 역량을 갖추어야 하는지를 소개하고 있다. 두 번째 세션 "Learning outcomes and outcome-based education"은 학습성과의 필요성을 논 의하고 구체적인 학습성과 모델과 전략을 소개하고 있다. 세 번째 세션 “Organising the learning programme"은 교육과 정이 어떻게 구성되는지 소개하고 교육과정을 계획할 때 고 민해야 하는 핵심적인 요소들을 10 가지 질문으로 제시하고 있다. 또한 우리나라에서도 깊이 있게 논의되고 있는 학생 중

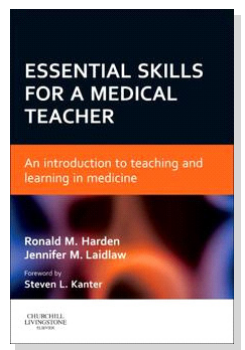

심의 통합교육과정, 핵심 교육과정(core curriculum), 일터 기반 학습(work-based learning)에 대한 구체적인 가이드를 제공하며, 마지막으로 실제 교육과정 맵 예시를 통해 그 유용 성을 언급하고 있다. 네 번째 세션 "Facilitating learning"은 효과적인 교수법을 선택할 때 고려해야 할 요소들을 안내하 고, 강의, 소집단학습, 자기주도학습, 이러닝, 동료 및 협력학 습 등 다양한 교수법 각각의 특징과 장점, 주의해야 할 점, 실 제 수업 장면에서 교수가 담당해야 할 역할 등을 구체적으로 설명하고 있다. 특히 임상 장면에서의 교수-학습을 별도의 장 으로 다루어 임상교육을 담당하는 교수에게 유용한 정보를 제공한다. 다섯 번째 세션 "Assessing the progress of the learner"는 누구를, 왜, 무엇을, 어떻게, 언제, 어디에서 평가 해야 하는지 6가지 질문에 대한 답을 제시하고 있다. 또한 지 필, 임상수행평가를 위한 다양한 방법과 포트폴리오 평가, 입 학사정 방법, 교육과정 평가에 대한 정보도 제공해 준다. 마지

Korean J Med Educ 2014 Dec; 26(4): 335-336.

http://dx.doi.org/10.3946/kjme.2014.26.4.335

eISSN: 2005-7288

(C) The Korean Society of Medical Education. All rights reserved.

This is an open-access article distributed under the terms of the Creative Commons Attribution Non-Commercial License (http://creativecommons.org/ licenses/by-nc/3.0/), which permits unrestricted non-commercial use, distribution, and reproduction in any medium, provided the original work is properly cited. 
막 여섯 번째 세션 “Today's teacher and tomorrow's doctors"는 의학교육이 어떻게 변화되었는지, 그렇기에 내일의 의사를 양성하는 교수들이 어떠한 역량을 갖춰야 하는지를 다시 한 번 정리해 준다.

이 책은 일반적인 교육학 이론이 아닌 의학교육 현장에서 바로 적용할 수 있는 'essential skills'을 담고 있다. 소개하는 예시들과 활용방법 역시 모두 저자들의 실제 의학교육 경험 에 기반하여 작성되었기 때문에 쉽게 접근하여 이해할 수 있
을 것이다. 이 책을 통해 보다 많은 의과대학 교수들이 의학교 육의 방향을 확인하고 'good teacher', 더 나아가 'excellent teacher'로 학생들에게 기억되기를 기대한다.

조아라, 가톨릭대학교 의과대학 의학교육학과

A Ra Cho, Department of Medical Education,

The Catholic University of Korea College of Medicine,

Seoul, Korea 